\title{
Influence of Substrate Processing and Interfacial Polymerization Conditions on the Surface Topography and Permselective Properties of Surface-Patterned Thin-Film Composite Membranes
}

\author{
Sajjad H. Maruf, ${ }^{1, *}$ Alan R. Greenberg, ${ }^{1}$ and Yifu Ding ${ }^{1,2, *}$ \\ ${ }^{1}$ Membrane Science, Engineering and Technology Center and \\ Department of Mechanical Engineering, \\ University of Colorado, Boulder, CO 80309-0427, USA \\ ${ }^{2}$ Materials Science and Engineering Program, \\ University of Colorado, Boulder, CO 80309-0596, USA
}

\begin{abstract}
The influence of substrate topography and interfacial polymerization (IP) conditions were investigated during the fabrication of patterned thin-film composite (TFC) membranes. Aromatic and semi-aromatic polyamide layers were formed atop patterned ultrafiltration (UF) membrane supports by IP using different concentrations of m-phenylenediamine (MPD) or piperazine (PIP) in water of $0.01-2 \% \mathrm{w} / \mathrm{v}$ with a fixed concentration of trimesoyl chloride in hexane of $0.1 \% \mathrm{w} / \mathrm{v}$. For all conditions evaluated, TFC membranes with regular surface patterns were achieved by maintaining amine soaking time and IP reaction time within $120 \mathrm{~s}$. Importantly, the surface topography of the patterned TFC membranes was determined to be independent of IP reaction time. Characterization of the morphological details suggests non-conformal growth of the barrier layer on the patterned UF substrates. Results indicate that the extent of such non-conformal growth can be reduced by decreasing the amine concentration as well as by choosing an amine monomer such as PIP that produces a thinner semi-aromatic barrier layer. The overall findings of this study provide a means for achieving desired surface features for specific membrane applications.
\end{abstract}

\footnotetext{
${ }^{*}$ Corresponding authors: Department of Mechanical Engineering, 427 UCB, University of Colorado, 1111 Eng. Drive, Boulder, CO 80309-0427; Tel.: +1 303492 2036; E-mail addresses: Sajjad.Maruf@Colorado.Edu; and Yifu.Ding@Colorado.Edu; Fax: +1 303-492-3498.
} 


\section{Introduction}

Thin-film composite (TFC) membranes are commonly used in reverse osmosis (RO) and nanofiltration (NF) processes for applications including desalination, wastewater treatment, and organic fractionations [1-3]. Despite the significant progress achieved, these membrane-based processes remain relatively energy intensive [4]. Approaches that can reduce the operational costs are critically needed for these membrane-based processes to be adopted on a much larger scale.

Liquid-based separation processes generally suffer from performance decline associated with the membrane fouling. Reduction of membrane fouling is one of the most challenging tasks affecting the field and one that offers the prospect of improving the energy efficiency of the separation processes in a substantial way $[5,6]$. The key to fouling mitigation is control of the interactions between the foulants and the membrane surfaces. In this regard methods that can enhance the back-diffusion of the foulants away from the membrane surface during separation are particularly promising for fouling reduction. Recently, studies have demonstrated that the presence of periodic surface patterns can enhance the fluid shear at the membrane surface [7], even though more fouling was observed at the concave sites. This results in overall improved antifouling behavior for ultrafiltration (UF) and microfiltration (MF) membranes against colloidal particles, proteins, and biological cells [8-10]. Given the general nature of the pattern-enhanced shear effect, it is expected that surface patterns, once successfully incorporated onto TFC membranes, will also be effective at reducing concentration polarization and scaling.

In the above-cited studies, the sub-micron surface patterns were directly imparted onto commercial UF membranes with nanoimprint lithography (NIL), a relatively low-cost and potentially scalable fabrication method. The underlying pattern-replication mechanism is the porosity-enhanced plastic deformation of the membranes during the NIL process, and thus is 
generally applicable to UF and MF membranes. UF or MF membranes fabricated from glassy (e.g. polyethersulfone (PES)) or semi-crystalline (e.g. PVDF) polymers and with porosities $\sim 80 \%$ will have yield strengths $\left(\sigma_{\mathrm{y}}\right)$ of $\sim$ several MPa at room temperature. Under mechanical loading at a stress level above $\sigma_{\mathrm{y}}$, such porous membranes will display an extended plastic deformation plateau until a densification stage is reached. Such membrane plasticity allows mechanically patterning (deforming) the membrane surface with NIL, even at temperatures far below the glass transition temperature $\left(T_{g}\right)$ or the melting temperature $\left(T_{m}\right)$ of the polymer. Furthermore, the geometry of the pattern achieved at the membrane surface (corresponding to the degree of local plastic deformation) can be tuned by adjusting the NIL process variables: pressure, temperature, and time [11].

However, the NIL methods developed for surface patterning of UF and MF membranes cannot be directly applied to commercial TFC membranes, which typically have an ultrathin, crosslinked barrier layer (most commonly polyamide) atop a porous support layer (a UF or MF membrane in most cases). It is nearly impossible to plastically deform the membrane surface by employing high pressure without causing fracture in the barrier layer, which will result in membrane failure. To overcome this challenge, we recently demonstrated that surface patterning of TFC membranes can be successfully achieved by subsequently forming the barrier layer on a previously surface-patterned UF membrane support [12]. Specifically, the polyamide barrier layer is conveniently formed via an interfacial polymerization (IP) process that is the standard method for preparing TFC membranes [13,14].

Despite this successful demonstration, the processing-structure-property relationships of this new methodology remain largely unknown. Knowledge of the chemical, physical, [15-17], and topographic properties $[18,19]$ of the barrier layer is crucial for applications of the resulting 
TFC membranes. Recent work has demonstrated that the magnitude of the antifouling effect directly correlates with the topographic features of the surface-patterned membranes [10,20]. Here we report systematic experimental studies of the morphological properties of the surface-patterned TFC membranes as a function of both the conditions and chemistry of the IP process as well as of the topography of the patterned UF substrates.

\section{Materials \& Methods}

\subsection{Materials}

In this study, a PES UF membrane (PW, GE Water and Infrastructure) was used as a substrate for fabricating all the TFC membranes. The as-received UF membrane has a molecular weight cutoff (MWCO) of $\sim 15.4 \mathrm{~kg} / \mathrm{mol}$, determined from exclusion measurements using polyethylene glycols (PEG) of different molecular weight [9]. The membranes were not subjected to any pre-treatment prior to either (1) NIL to fabricate patterned UF substrates or (2) IP to fabricate flat TFC membranes as control samples.

Unless otherwise specified, all reagents and chemicals were analytical grade with purity over 99\%. 1, 3-phenylenediamine (MPD), piperazine (PIP, 99.5\%), trimesoyl chloride (TMC, 99 $\%$ ), triethylamine (TEA, $99.5 \%$ ), and (+) 10-camphor sulfonic acid (CSA, 99.0\%) were purchased from Sigma Aldrich (US), and bio-grade hexane and sodium chloride were obtained from Fisher Scientific (Santa Clara, CA, US). Deionized (DI) water was supplied in-house from a RiOs-DI water system (EMDMillipore) with a resistivity of $10 \mathrm{M} \Omega-\mathrm{cm}$.

\subsection{Fabrication of surface-patterned TFC membranes}

As shown schematically in Fig. 1, surface-patterned TFC membranes were fabricated via a two-step process: (1) surface patterning of the PES UF membranes via NIL, and (2) forming the 
thin barrier layer atop the patterned UF membrane supports using IP. Surface-patterning of the UF membranes with NIL has been previously described in detail [11]. Under mechanical compression at elevated temperature and pressure (Fig. 1), plastic deformation occurs at the membrane-mold contact area, replicating the sub-micron features on the Si mold. In this study, patterning of the UF membranes was carried out in an Eitrie 3 (Obducat, Inc.) nanoimprinter, which provides uniform compression (1\% variation over a 3 -inch wafer size) $[21,22]$.

i. Patteming the UF membranes via NIL

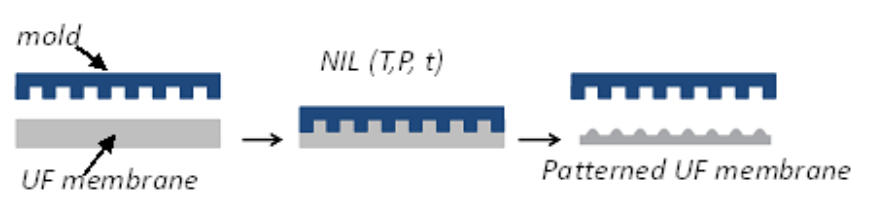

ii. IP on the pattemed UF membrane

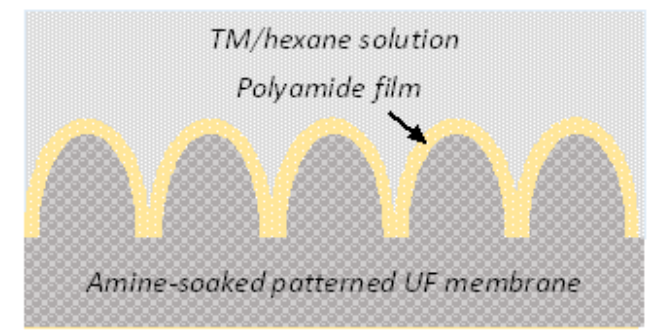

iii. Two IP reaction systems used

Figure 1. A schematic illustration of the process used to fabricate the patterned TFC membranes: (i) surface patterning the UF membrane with NIL, and (ii) forming a barrier layer via IP on the patterned UF support. The two IP reaction systems used are shown in (iii).

A Si mold containing parallel line-and-space grating patterns (a periodicity of $575 \mathrm{~nm}$, line width of $210 \mathrm{~nm}$ and groove depth of $180 \mathrm{~nm}$ ) was used. Prior to the NIL process, the Si mold was treated with a NanoStrip ${ }^{\circledR}$ solution (stabilized 3:1 concentrated sulfuric acid to hydrogen peroxide solution) to remove any organic residue. The UF membranes were imprinted under 4 MPa pressure for $3 \mathrm{~min}$ at 80,120 and $175^{\circ} \mathrm{C}$ to impart different pattern heights onto the membranes. For all NIL conditions, the demolding temperature was kept constant at $40^{\circ} \mathrm{C}$. As a control study, a flat Si wafer was used to "imprint" the UF membrane under identical conditions 
as those for the Si mold to create "flat" UF substrates (Table 1). All the imprinted UF membranes were rinsed with and stored in DI water, and completely sealed under dark conditions prior to IP. The patterned UF membranes were then used as supports to fabricate the TFC membranes via IP using MPD (or PIP) and TMC, whose chemical structures and the corresponding polyamide layers formed are shown in Fig. 1c. The UF membrane sample area used was $1.2 \mathrm{~cm} \times 1.2 \mathrm{~cm}$ for all the experiments except those used in the filtration study, which were $2.5 \mathrm{~cm} \times 2.5 \mathrm{~cm}$. The protocol followed for IP can be summarized as follows. A UF support was taped onto a Si wafer with the skin layer (the patterned surface) facing upwards. The support was then placed in an aqueous amine (MPD or PIP) solution for different intervals (referred to as "amine-soaking time" or $t_{a s}$ ). The aqueous amine solution was prepared by adding MPD (or PIP) to a $100 \mathrm{~mL}$ TEA-CSA aqueous solution containing $2 \mathrm{~g}$ of TEA and $4 \mathrm{~g}$ CSA, to form $0.01,0.1$ and $2 \%(\mathrm{w} / \mathrm{v}$ ) of MPD (or PIP) solution. Note that CSA is commonly used to improve the absorption of the amine solution on the support membrane while TEA is used to accelerate the IP reaction [23, 24]. The aminesoaking time for a given UF membrane was varied between $8 \mathrm{~s}$ and $240 \mathrm{~s}$. Once removed from the aqueous amine solution, the UF membrane was gently air-blown to remove any excess solution on the membrane surface, and was then immediately submerged in a hexane solution containing $0.1 \%(\mathrm{w} / \mathrm{v}) \mathrm{TMC}$ for $8 \mathrm{~s}$ to $240 \mathrm{~s}$ (referred to as "IP reaction time" or $\left.t_{I P}\right)$. Finally, the membrane was cured in an oven at $70^{\circ} \mathrm{C}$ for $10 \mathrm{~min}$, and rinsed thoroughly with DI water. All prepared membranes were stored in DI water until testing.

\subsection{Membrane characterization}

The topography and morphology of the membrane samples were characterized with atomic force microscopy (AFM) and scanning electron microscopy (SEM). The AFM measurements (DI 3100, Bruker) were performed with tapping mode under ambient condition using Si cantilever 
probe tips (Veeco, RTESP). For patterned membranes, the AFM scan direction was kept perpendicular to the grating lines so that accurate mapping of the surface patterns or profiles could be obtained. For each membrane sample, at least 8 AFM measurements were taken on randomly selected areas across the surface. The field-emission SEM (FE-SEM, Zeiss, Supra 60) measurements were carried out to image both the surface as well as the cross-section of selected membranes. For cross-sectional SEM measurements, the membrane samples were prepared by freeze-fracturing under liquid $\mathrm{N}_{2}$ after carefully removing the non-woven web. All of the samples were dried in a vacuum oven over night and then coated with a $\sim 5 \mathrm{~nm}$ thick gold layer before SEM evaluation.

TEM measurements (Jeol 1230) were used to characterize the cross-sections of the barrier layers formed on the TFC membranes. Samples were prepared by cryo-microtome (Leica Ultracut S ultramicrotome) with a diamond knife. Membrane samples were immersed in LR White resin for $24 \mathrm{~h}$, placed into a gelatin capsule filled with LR White resin, and finally cured at $60{ }^{\circ} \mathrm{C}$ for overnight. For patterned membranes, the microtoming direction was perpendicular to the grating lines, and the thickness of the microtomed samples was approximately $70-90 \mathrm{~nm}$. All images were acquired at $80 \mathrm{kV}$ using Gatan CCD cameras, either a cooled 967 slow-scan or a highresolution Orius SC1000A.

Attenuated Total Reflectance-Fourier transform infrared (ATR-FTIR) spectroscopy (Nicolet 6700, Thermo Fisher Scientific) was used to characterize the surfaces of the membranes. Spectra of the PES UF membrane support and representative TFC membranes were measured between 700 to $2200 \mathrm{~cm}^{-1}$ with $1 \mathrm{~cm}^{-1}$ resolution. Each sample was rinsed and soaked in DI water for $24 \mathrm{~h}$, and dried in a vacuum oven prior to the ATR-FTIR measurements. 
The $T_{g}$ of the polyamide barrier layer on selected TFC membranes was measured using a nano-TA (Anasys Instruments Inc.) technique. A detailed description of the principle underlying the nano-TA methodology and its application to polymer thin films including barrier layers on TFC membranes can be found in refs $[25,26]$. In this study, a heating rate of $2{ }^{\circ} \mathrm{C} / \mathrm{s}$ was applied for all of the $T_{g}$ measurements. For each sample, measurements at multiple locations across the membrane surface were carried out, and the mean value and standard deviation reported.

Permselective properties of both the UF support and TFC membranes were characterized using a Sterlitech HP4750 dead-end filtration cell (Sterlitech, WA) with high-pressure $\mathrm{N}_{2}$ supplying the required pressure. The permeation mass flowrate was obtained by weighing samples over timed intervals (every $10 \mathrm{~min}$ ) using an automated electronic balance (PI-225DA, Denver Instrument). For a membrane sample, DI water filtration was first carried out under a 100 psi pressure for 3-4 h until the steady-state flux was reached. Subsequently, the feed was switched to an aqueous sodium chloride solution $(1 \mathrm{~g} / \mathrm{L})$, and permeate was collected at $689 \mathrm{kPa}$ for another 2 h. The salt rejection for a given membrane, $R_{o}$, was calculated from $R_{o}(\%)=\left(1-C_{p} / C_{f}\right)$, where $C_{p}$ and $C_{f}$ are the salt concentration for permeate and feed, respectively. Conductivities of the feed and permeate solutions were measured with an Oakton PCTestr series conductivity meter (Vernon Hills, IL), and $C_{p}$ and $C_{f}$ were obtained from the (conductivity-concentration) calibration curve prepared for the instrument. All of the filtration experiments were carried out at room temperature.

\section{Results and discussion}

Figure 2 shows representative results from the fabrication of surface-patterned TFC membranes. The surface of the virgin UF membranes (Fig. 2.a.1-2.a.3) was smooth, with an RMS roughness < $10 \mathrm{~nm}$ from AFM measurement (Fig. 2.a.3). Based upon MWCO measurements, the surface pores are estimated to be $2-3 \mathrm{~nm}$ in diameter, and could not be resolved by SEM or AFM. 
No noticeable surface roughness changes were observed for the UF membranes after "imprinting" with a flat wafer. These flat-wafer compressed membranes served as supports for IP, and the resulting non-patterned TFC membranes also evidenced flat surfaces (Fig. 2.b.1-2.b.3). The yellowish color of the membrane surface (Fig. 2.b.1) was attributed to the presence of residual amine groups, which were confirmed from the ATR-FTIR measurements [12]. Note that flatwafer-compressed UF substrates serve best as control samples, in comparison to as-received UF substrates, because the NIL process alters the pore-structure throughout the UF support in addition to creating patterns at the membrane surface [11]. Thus, comparing membranes imprinted with a flat wafer and a patterned $\mathrm{Si}$ mold enables the influence of surface patterning on membrane performance to be assessed without the confounding effect of support structure differences.
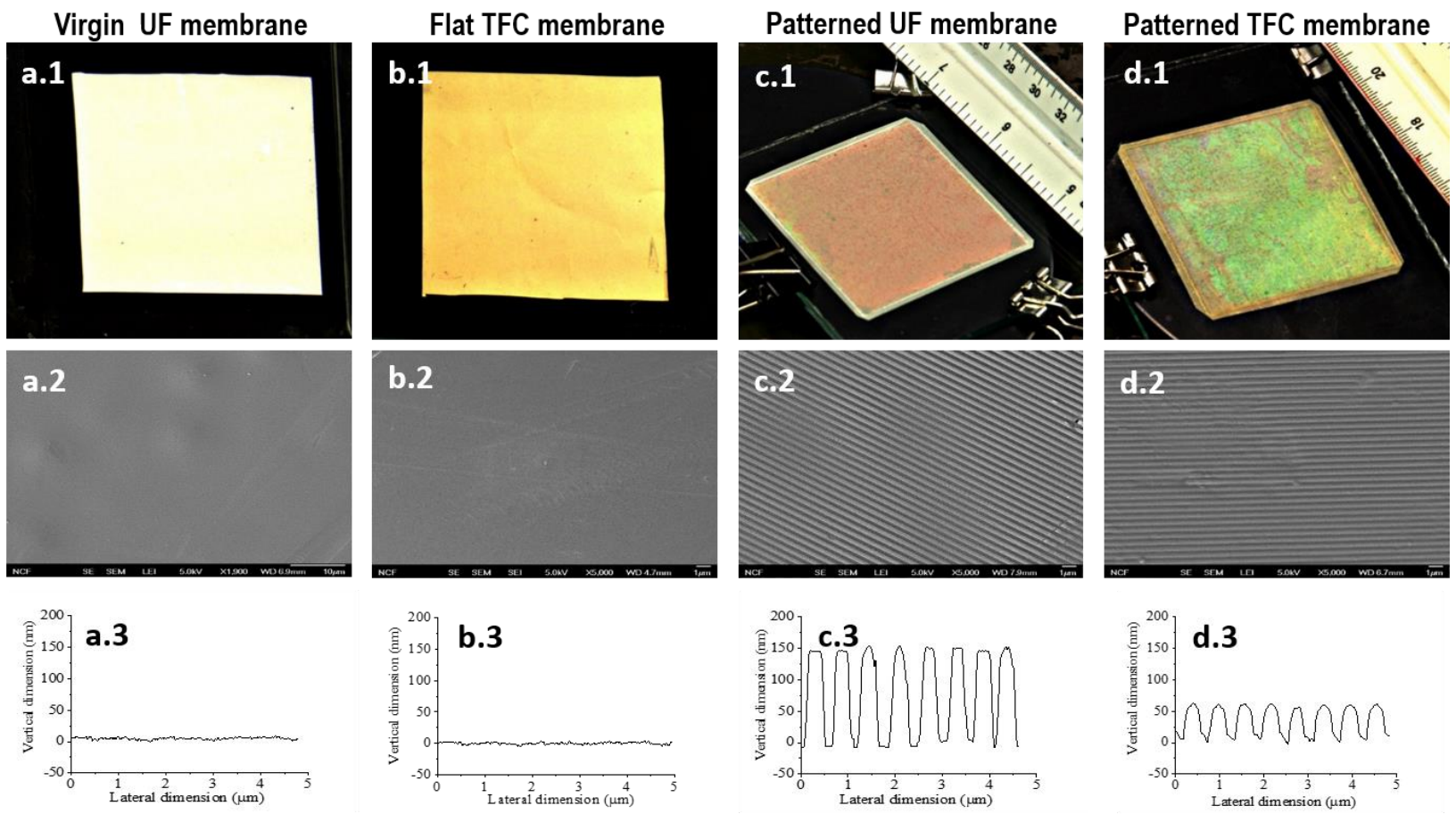

Figure 2. Top row: photographs of a virgin PES UF membrane (a.1), a non-patterned TFC membrane (b.1), a patterned UF membrane support (c.1), and a patterned TFC membrane (d.1). Middle row: top-down SEM images a.2-d.2 corresponding to the samples in a.1 -d.1. Bottom row: cross-sectional profiles from AFM scans (a.3-d.3) of the membrane surfaces corresponding to the samples in a.1 -d.1. 
Periodic line-and-space grating patterns were successfully "imprinted" onto the UF membrane via NIL with a patterned Si mold. The distinct color of this patterned UF membrane (Fig. 2.c.1) was caused by the diffraction of light from these periodic structures (Fig. 2.c.2). The homogeneity of the color suggests that the patterns were uniform across the membrane surface. For the representative sample shown in Fig. 2.c, the pattern heights achieved were $\sim 150 \mathrm{~nm}$ (Fig. 2.c.3). In contrast, the pattern height of the patterned TFC membrane (Fig. 2.d.1-2.d.3) was $\sim 60$ $\mathrm{nm}$, less than $50 \%$ of that of the UF support. Clearly, the topography of the surface pattern achieved on the TFC membranes will depend on both the topography of the UF support and the IP process conditions, which are described below.

\subsection{Effect of NIL conditions}

PES UF membranes with three different pattern heights but identical periodicity were fabricated by nanoimprinting the virgin membranes at different temperatures. Table 1 shows the NIL conditions and the corresponding pattern heights (referred to as $h_{U F}$ ) that were generated. With an increase of imprinting temperature from 80 to $175{ }^{\circ} \mathrm{C}$, hUF increased from $\sim 25$ to $\sim 151$ nm. From SEM images and AFM scans (Fig. S1), the patterns were uniform with very low local roughness on the mesa and trenches of the patterned lines. From our detailed mechanics analysis, the deformation of the UF membranes under NIL conditions can be successfully described by the relationships developed for open-cell polymer foams [11]. More precisely, the membrane displays more plastic deformation at higher imprinting temperature, with other conditions (pressure and time) held constant. Note that the plastic deformation of the UF membranes occurs not only at the surface but also throughout the membrane thickness, causing reduction in the overall porosity and permeance of the membrane. From the filtration experiments with $\mathrm{NaCl}$ solutions, these imprinted UF membranes showed very low salt rejection (Table 1), and relatively high permeance as 
compared with the TFC membranes discussed later. All three patterned membranes (sub-1, sub-2 and sub-3) were used as supports to fabricate TFC membranes.

Table 1. Surface patterned UF membrane supports fabricated under varying NIL conditions.

\begin{tabular}{ccccc}
\hline $\begin{array}{c}\text { UF } \\
\text { support }\end{array}$ & $\begin{array}{c}\text { NIL conditions } \\
(\mathbf{T} / \mathbf{P} / \text { time })\end{array}$ & $\begin{array}{c}\boldsymbol{h}_{\boldsymbol{U}} \\
(\mathbf{n m})^{\mathbf{a}}\end{array}$ & $\begin{array}{c}\text { Permeate flux } \\
\left(\mathbf{L m}^{\mathbf{2}} \mathbf{h}^{\mathbf{- 1}}\right)\end{array}$ & $\begin{array}{c}\text { Salt rejection } \\
(\boldsymbol{\%})\end{array}$ \\
\hline Flat & $120^{\circ} \mathrm{C} / 4 \mathrm{MPa} / 3 \min$ & NA & 158.6 & 2.3 \\
Sub-1 & $80^{\circ} \mathrm{C} / 4 \mathrm{MPa} / 3 \min$ & $25.1 \pm 0.6$ & 199.0 & 2.1 \\
Sub-2 & $120^{\circ} \mathrm{C} / 4 \mathrm{MPa} / 3 \min$ & $65.4 \pm 1.0$ & 179.7 & 2.8 \\
Sub-3 & $175^{\circ} \mathrm{C} / 4 \mathrm{MPa} / 3 \min$ & $150.9 \pm 0.9$ & 155.4 & 3.4 \\
\hline
\end{tabular}

${ }^{a}$ Values represent mean and standard deviation based on a sample size of four.

${ }^{\mathrm{b}}$ Filtration conditions: transmembrane pressure of $689.5 \mathrm{kPa}$ and a $1 \mathrm{~g} / \mathrm{L} \mathrm{NaCl}$ feed solution.

Formation of the polyamide films was verified by comparing the FTIR spectra from the surface of the patterned UF supports (using sub-2 as an example) and that of the patterned TFC membranes using 2\% MPD and 2\% PIP (Figure 3). For sub-2, the absorption peaks at 1151, 1244, and $1490 \mathrm{~cm}^{-1}$ were the vibrational signatures of the $\mathrm{SO}_{2}$ group, $\mathrm{C}-\mathrm{O}-\mathrm{C}$, and $\mathrm{C}-\mathrm{S}$, respectively $[27,28]$. All of these peaks characteristic of PES were also present in the spectra of both surfaces of the TFC membranes. The estimated penetration depth of the ATR-FTIR spectroscopy is about 1- $5 \mu \mathrm{m}$ in the wavelength region of interest, thus making the spectrum obtained from the TFC membranes a combination of the polyamide barrier layer and the underlying PES support. More importantly, the vibrational signatures associated with the polyamide layer were found for $2 \%$ MPD on sub-2 at $\sim 1540$ and $1680 \mathrm{~cm}^{-1}$, representing stretching of amides I and II, respectively $[28,29]$. The characteristic peak at $1628 \mathrm{~cm}^{-1}$ for $2 \%$ PIP on sub-2 corresponds to the PIP-based amide groups [30,31]. Both spectra confirm the formation of polyamide barrier layers on the patterned TFC membranes using 2\% MPD and 2\% PIP. For lower concentration amine systems, 
the vibrational signatures of the barrier layers were challenging to observe as they become ultrathin.

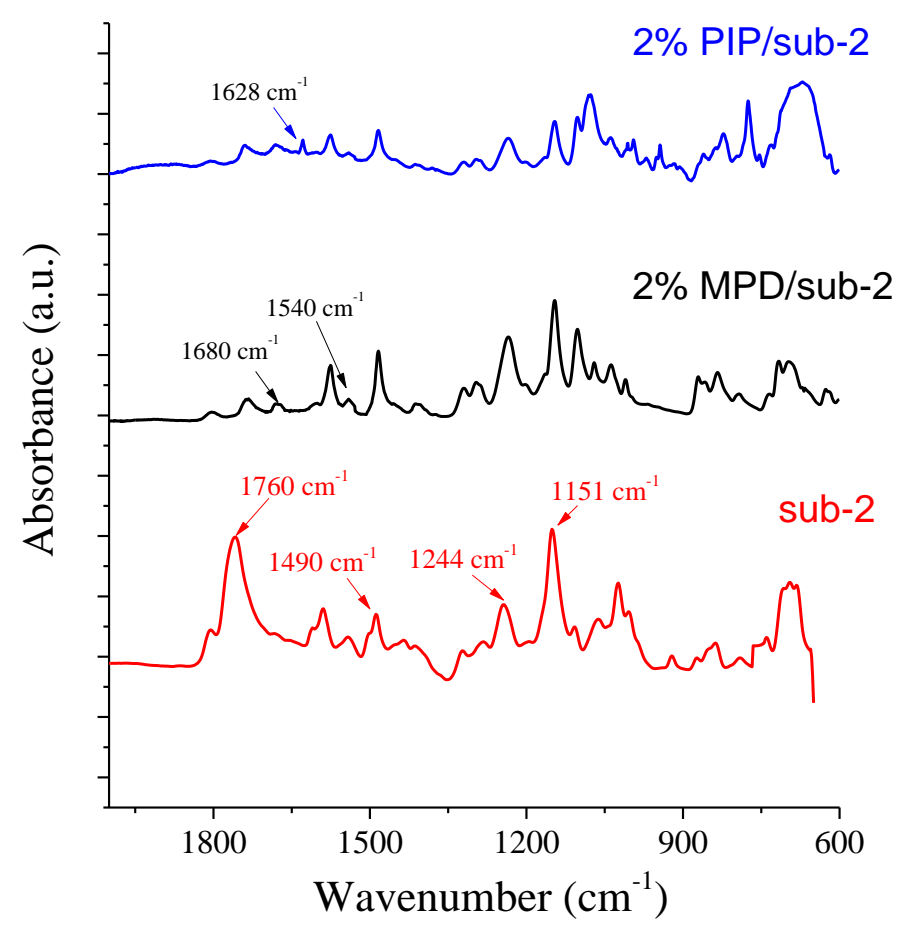

Figure 3. Comparison of representative ATR-FTIR spectra of a patterned UF support (sub-2), and patterned TFC membranes prepared with $2 \% \mathrm{MPD}$ and $2 \%$ PIP. For both patterned TFC membranes the $t_{a s}=120 \mathrm{~s}$, and $t_{i p}=8 \mathrm{~s}$.

\subsection{Effect of IP conditions}

The polyamide barrier layer was formed by first soaking a given UF support in aqueous amine solution for a desired interval $\left(t_{a s}\right)$ and then immersing the amine-absorbed support membrane in a hexane solution containing TMC for another interval $\left(t_{i p}\right)$. Using the MPD (2 $\%$ )/TMC system as an example, we first examined the influence of $t_{a s}$ on the morphology of the patterned TFC membranes. Figure 4 shows the SEM images of the TFC membranes fabricated by the IP process with $2 \%$ MPD/TMC system on the sub-2 support, with varying $t_{a s}$ but identical $t_{i p}$ 
(8s). The results show that TFC membranes with uniform surface patterns were obtained when $t_{a s}$ was no longer than $120 \mathrm{~s}$; the patterned lines appear to be smooth with average pattern heights of $\sim 35 \mathrm{~nm}$ (Figs. 4a and 4b). In stark contrast, the membrane fabricated with $t_{a s}=180 \mathrm{~s}$ displayed local roughness along the periodic line patterns (Fig. 4c). For the membrane fabricated with $t_{a s}=$ $240 \mathrm{~s}$ (Fig. 3d), the roughness became more dominant and nearly masked the periodic patterns. From the higher magnification views (Fig. S2), the random roughness appeared similar to the “nodular" structures often observed for polyamide barrier layers on TFC membranes [19,32].

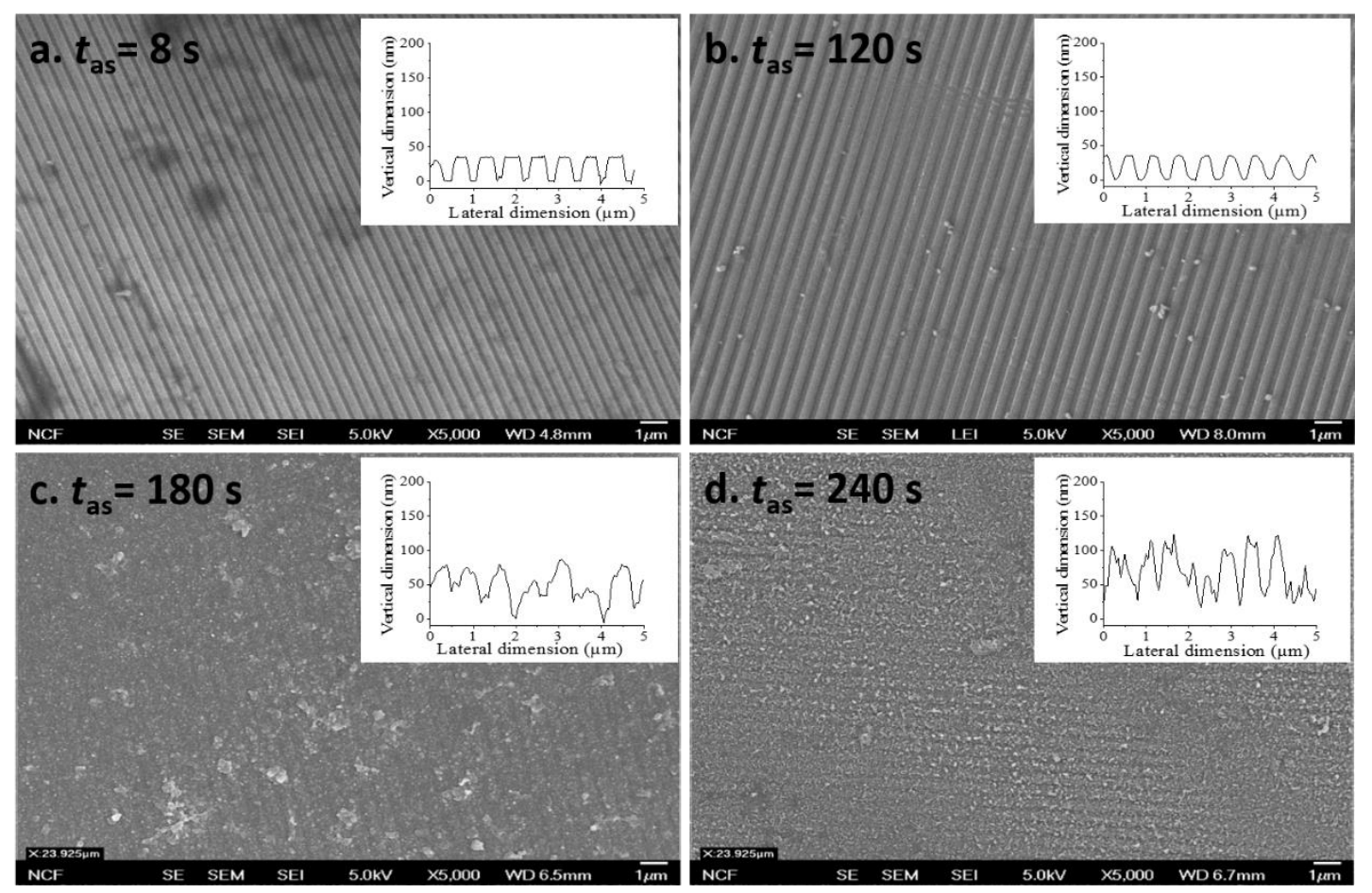

Figure 4. SEM images of the surface-patterned TFC membranes fabricated with different tas: (a) $8 \mathrm{~s}$, (b) $120 \mathrm{~s}$, (c) $180 \mathrm{~s}$, and (d) $240 \mathrm{~s}$. All other conditions were held constant: MPD (2\%)/TMC system; sub-2 substrate; $t_{i p}=8 \mathrm{~s}$. Inset in each figure is the AFM scan profile from the corresponding membrane surface. A higher resolution image of (d) is presented in Fig. S2.

The impact of tas on the surface morphology of the polyamide barrier layer has generally been deemed as unimportant and thus overlooked in the open literature. In our study, $t_{a s}$ appears to have a significant influence on the surface topography of the barrier layer. We also verified that 
random roughness starts to become significant for flat substrates after $120 \mathrm{~s}$ of amine soaking. Since the main goal of the present study was to achieve well-defined periodic structures on the TFC membranes, we kept $t_{a s}=120 \mathrm{~s}$ in all of the following experiments where such random roughness is not dominant. For lower concentration MPD systems as well as all of the PIP systems considered, the reaction rates are expected to be slower than the $2 \%$ MPD systems. This suggests that $120 \mathrm{~s}$ of amine soaking time will likewise not cause significant local roughness on these membranes, which is indeed confirmed experimentally.

Next, we examined the influence of $t_{i p}$ (or equivalently, the soaking time within the TMC/hexane solutions) on the surface topography of the patterned TFC membranes. Figure 5 shows the SEM images and corresponding AFM scan profiles for TFC membranes prepared with varying $t_{i p}$, with the remaining variables held constant: $2 \%$ MPD/TMC system, sub-2 support, and $t_{a s}=120 \mathrm{~s}$. Interestingly, AFM measurements indicated that the pattern heights obtained appear to be $\sim 35 \mathrm{~nm}$ for all of the TFC membranes, i.e., independent of $t_{i p}$ (from $8 \mathrm{~s}$ to $120 \mathrm{~s}$ ). In contrast, the local roughness along the lines and trenches becomes increasingly noticeable with increasing $t_{i p .}$ 


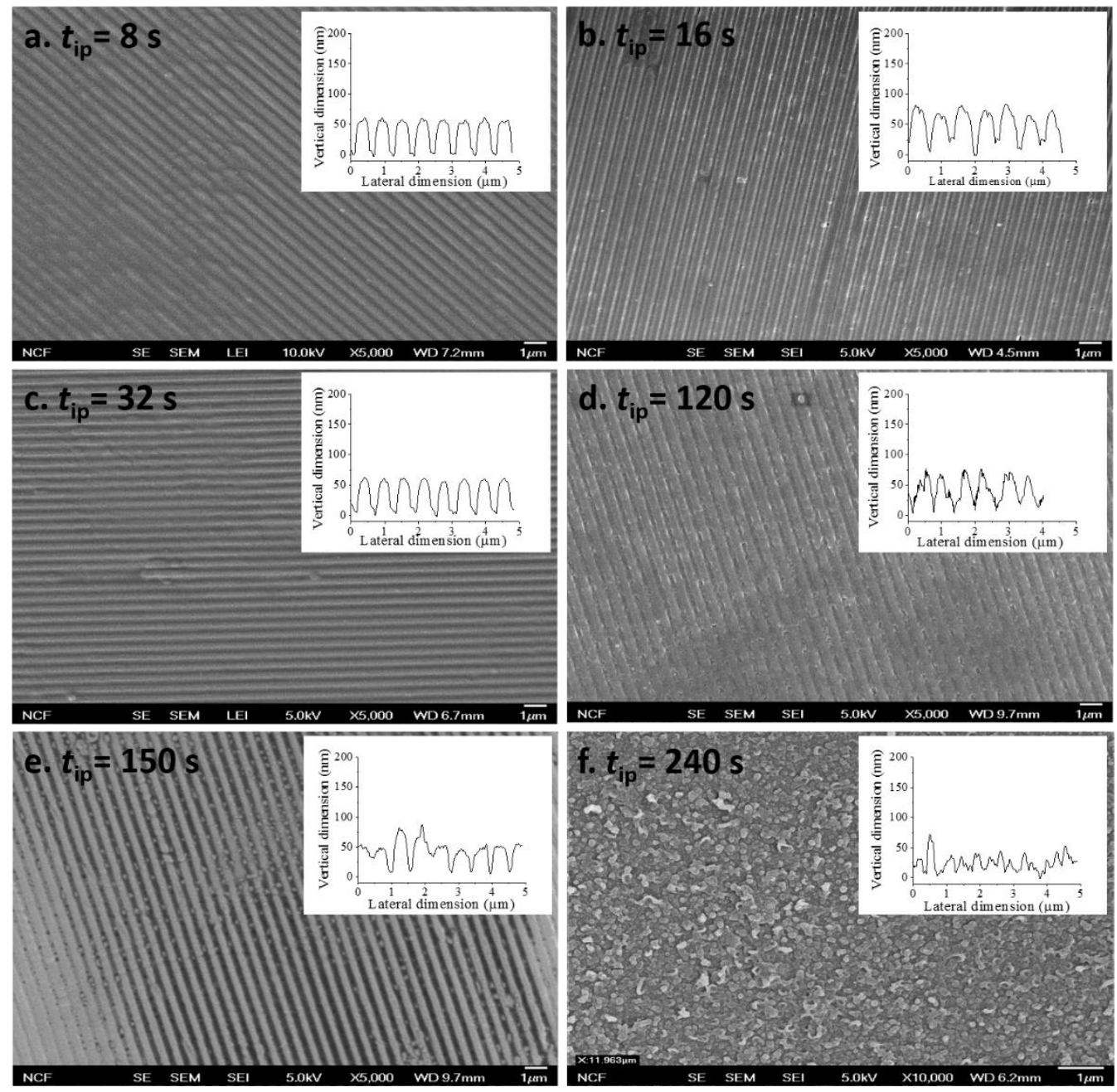

Figure 5. SEM images of the surface-patterned TFC membranes fabricated with different IP reaction time, $t_{i p}$, as marked on each figure. All other conditions were held constant: $2 \%$ MPD /TMC system; sub-2 substrate; $t_{a s}=120 \mathrm{~s}$. The inset in each figure is the AFM scan profile from the corresponding membrane surface.

Table 2 summarizes the pattern heights and the associated local roughness obtained for the TFC membranes with different $t_{i p}$ on all three patterned UF supports. Consistently, the pattern heights of the TFC membrane (referred to as $h_{T F C}$ ) appeared to be relatively independent of $t_{i p}$; however, local roughness increased from a few to several $\mathrm{nms}$ as $t_{i p}$ increased to $120 \mathrm{~s}$. For membranes prepared with $t_{i p}>120 \mathrm{~s}$, nodular structures started to form amidst the regular surface patterns (Fig. 5e), which evolved into a "ridge-and-valley" structure when $t_{i p}=240 \mathrm{~s}$ (Fig. 5f). A 
similar trend was observed for the membranes prepared using sub-3, with all other conditions kept constant. It appears that both $t_{i p}$ and tas have similar influence over the pattern roughness and topography, which most likely can be attributed to the kinetics of the IP process.

Table 2. Pattern height and local roughness of the surface-patterned TFC membranes, prepared with varying $t_{i p}$ on different substrates. MPD concentration was $2 \%$ and the $t_{a s}=120 \mathrm{~s}$.

\begin{tabular}{cccc}
\hline $\begin{array}{c}\text { UF } \\
\text { support }\end{array}$ & $\begin{array}{c}\boldsymbol{t}_{\boldsymbol{i}} \\
(\mathbf{s})\end{array}$ & $\begin{array}{c}\boldsymbol{h}_{\text {TFC }} \\
(\mathbf{n m})^{\mathbf{a}}\end{array}$ & $\begin{array}{c}\text { Local } \\
\text { roughness }\end{array}$ \\
\hline & 8 & $17 \pm 2.6$ & $1.2 \pm 0.6$ \\
Sub-1 & 16 & $17.6 \pm 1.9$ & $2.6 \pm 1.1$ \\
& 32 & $17.5 \pm 1.5$ & $6.1 \pm 1.2$ \\
& 120 & $15.3 \pm 1.8$ & $7.3 \pm 0.6$ \\
\hline & 8 & $32.5 \pm 1.6$ & $1.6 \pm 0.9$ \\
Sub-2 & 16 & $35.2 \pm 0.6$ & $2.8 \pm 0.5$ \\
& 32 & $36 \pm 1.2$ & $6.9 \pm 1.7$ \\
& 120 & $35.8 \pm 1.1$ & $8.1 \pm 1.4$ \\
\hline & 8 & $60.8 \pm 2.4$ & $1.8 \pm 1$ \\
Sub-3 & 16 & $62.5 \pm 1.6$ & $1.9 \pm 1.2$ \\
& 32 & $60.3 \pm 2.1$ & $5.6 \pm 0.8$ \\
& 120 & $57.5 \pm 2$ & $7.9 \pm 2.7$ \\
\hline
\end{tabular}

${ }^{\text {a }}$ Values represent mean and standard deviation based on a sample size of three.

${ }^{\mathrm{b}}$ The local roughness is estimated from AFM profiles along the patterned lines and trenches.

For a typical IP process, the thickness of the barrier layer will be dependent upon the monomer concentrations $[18,33,34]$, which might be an effective variable in controlling the surface topography of the patterned TFC membranes. We determined that even for the $0.01 \%$ MPD systems, $h_{T F C}$ was independent of $t_{i p}$ within this time frame, i.e. $8 \mathrm{~s}$ is sufficient for $h_{T F C}$ to reach a steady state. This observation is consistent with a recent study by Matthews et al. [35]. Using diffuse reflectance spectroscopy and Rutherford backscattering spectroscopy, they found that the barrier layer thickness reached a steady state within $10 \mathrm{~s}$, even for very dilute systems such as $0.02 \% \mathrm{MPD} / 0.1 \% \mathrm{TMC}$. 


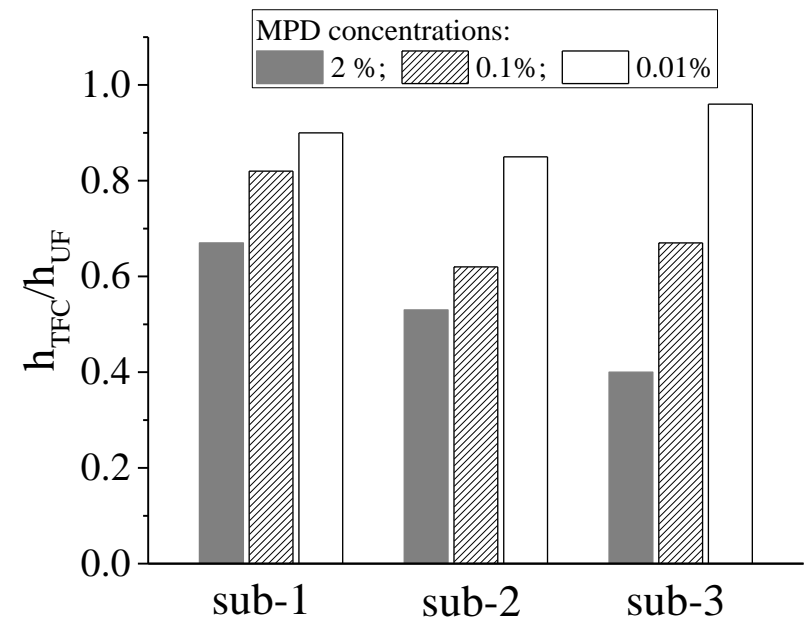

Figure 6. Ratio between the pattern height of the TFC membranes $\left(h_{T F C}\right)$ and those of the corresponding UF support $\left(h_{U F}\right)$, for membranes fabricated with varying MPD concentrations: $2 \%$ (solid bars), $0.1 \%$ (shaded bars), and $0.01 \%$ (empty bars). hTFC was the mean value for the membranes prepared with different $t_{i p}(8 \mathrm{~s}, 16 \mathrm{~s}, 32 \mathrm{~s}$, and 120s), but with identical MPD concentration and UF substrates. Accordingly, $h_{U F}$ represents the mean value of the four substrates used for the four different $t_{i p}$. For all these systems, the TMC concentration is $0.1 \%$, and the $t_{a s}$ $=120 \mathrm{~s}$.

Figure 6 summarizes and compares the ratio of the pattern heights between the TFC membrane $\left(h_{T F C}\right)$ and the corresponding UF support $\left(h_{U F}\right)$ used for varying MPD concentrations on all the three UF supports. Note that for each system (identical UF substrate and MPD concentration), $h_{T F C}$ was the mean value for the samples prepared with $t_{i p}$ ranging from $8 \mathrm{~s}$ to 120 s. Figure 6 shows that the pattern heights of the TFC membranes were smaller than that of the UF supports, which suggests the non-conformal growth of the barrier layer, i.e. the thickness within the trenches was most likely larger than that atop the mesas. For the $2 \%$ MPD systems, the pattern heights of the TFC membranes were $67 \%, 53 \%$, and $40 \%$ of sub-1, sub-2 and sub-3, respectively. In other words, the degree of non-conformal growth of the barrier layers appears to increase with the increase of pattern heights on the UF support. With decreased MPD concentration, the pattern heights of TFC membranes prepared on the identical UF supports increased. For the $0.1 \%$ MPD 
systems, the $h_{T F C} / h_{U F}$ were $82 \%, 62 \%$, and $67 \%$, for sub-1, sub-2 and sub-3, respectively. For the $0.01 \%$ MPD systems, the corresponding ratios were $90 \%, 85 \%$, and $96 \%$, i.e. the pattern heights of the TFC membranes approached that of the UF supports. Assuming the $h_{T F C} / h_{U F}$ ratio is an indication of thickness uniformity of the polyamide layer, using a lower concentration of MPD will lead to more conformal growth or formation of a more uniform barrier layer as well as taller patterns on the TFC membranes.
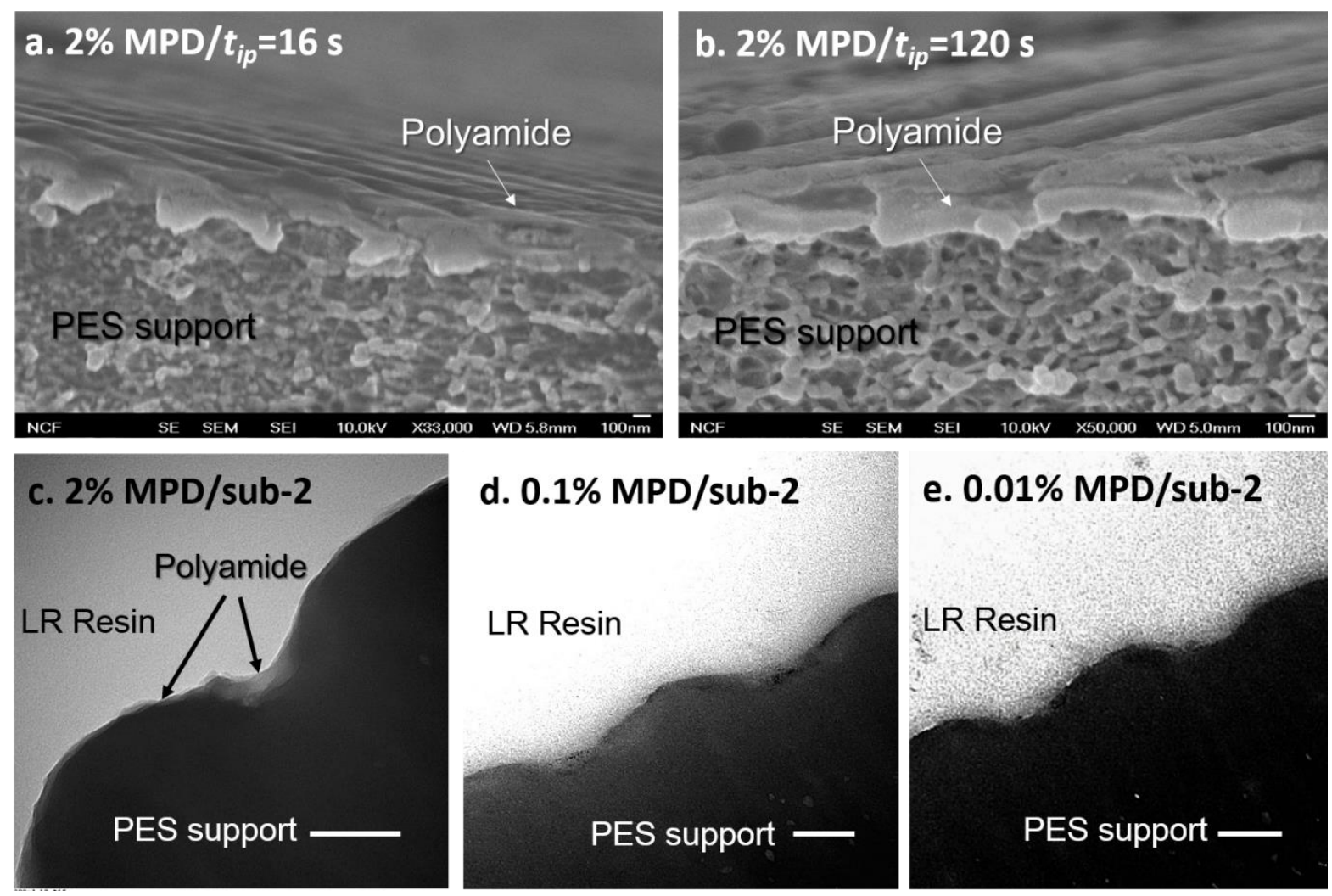

Figure 7. Representative cross-sectional images of the MPD-based TFC membranes fabricated on sub-2 under different conditions. SEM images of TFC membranes with a $t_{i p}$ of (a) $16 \mathrm{~s}$ and (b) 120 $\mathrm{s}$; each fabricated with $2 \%$ MPD and $t_{a s}=120 \mathrm{~s}$. TEM images of the TFC membranes fabricated with different MPD concentration but constant $t_{a s}=120 \mathrm{~s}$ and $t_{i p}=8 \mathrm{~s}$ (c) $2 \%$, (d) $0.1 \%$ and (e) $0.01 \%$; the scale bars in (c)-(e) represent $100 \mathrm{~nm}$.

Figures $7 \mathrm{a}$ and $7 \mathrm{~b}$ show representative cross-sectional SEM images of the TFC membranes prepared with $2 \%$ MPD on sub-2. Both images clearly show that a thin but dense and continuous layer of polyamide was formed atop the UF support. However, it is challenging to quantify barrier 
layer thickness and its uniformity across the patterned UF support. Thus, high-resolution TEM images were obtained for the patterned TFC membranes fabricated with different MPD concentrations (Fig. 7c-7e). With 2\% MPD, a continuous layer of polyamide was observed on the patterned substrate, with a thicker film formed within the trenches of the UF support (Fig. 7c). More specifically, the polyamide thickness in the trenches was $\sim 35 \mathrm{~nm}$ and $\sim 8 \mathrm{~nm}$ in the mesa regions. This non-conformal growth of the barrier layer resulted in a reduction of pattern height from $\sim 65 \mathrm{~nm}\left(h_{U F}\right)$ to $\sim 38 \mathrm{~nm}\left(h_{T F C}\right)$, consistent with the AFM measurements discussed above. Such non-uniform barrier layer thickness might be due to inherent 2-D growth on patterned UF substrates in comparison to 1-D growth on flat substrates, and/or more absorbed amine within the trenches of the patterns. At lower MPD concentrations, the polyamide layers appear very thin and are challenging to resolve unambiguously from the TEM images (Fig. 7d and 7e). By selectively dissolving the PES support, we could isolate continuous barrier layer films for the $2 \%$ MPD system. In contrast, isolation of the barrier layer was unsuccessful for lower concentration MPD systems. However, we note that all of these observations are consistent with the $h_{T F C} / h_{U F}$ ratio values described previously (Fig. 6).

Collectively, the above results show that by controlling $t_{a s}, t_{i p}$, NIL processing temperature, and MPD concentration, a range of patterned TFC membranes with identical polyamide chemistry can be fabricated with high pattern regularity. As expected, characterization of the chemical and physical properties of the barrier layer was difficult and required the use of new methodology such as nano-TA. Nano-TA is an AFM-based tool that can measure the softening temperature of thin films with high spatial resolution, and has been applied to determine the $T_{g}$ of the barrier layer and its evolution upon chemical degradation $[25,26]$. Using TFC membranes fabricated onto sub-2 supports, the $T_{g}$ of the barrier layer ranges between $186-193{ }^{\circ} \mathrm{C}$ (Fig. S3a), which is decidedly 
lower than that of the PES support $\left(\sim 220^{\circ} \mathrm{C}\right)$, but is within the range of barrier layer $T_{g}$ 's for commercial TFC membranes such as Filmtec XLE440 [26]. As with the ATR-FTIR and TEM measurements, it was difficult to employ nano-TA to accurately determine barrier layer $T_{g}$ 's of TFC membranes fabricated with a lower concentration of MPD given their small thickness.

\subsection{Permeation characteristics}

Filtration measurements with a salt solution were carried out to characterize the "tightness" of the barrier layer as well as overall performance of the membranes. Given the large group of the samples, we selected a series of TFC membranes prepared with sub-2 supports, as reported in Table 3. Note that the both permeate flux and salt rejection shown here are mean values during the first $2 \mathrm{~h}$ of filtration, using a one-pass dead-end filtration setup because of size (area) limitations of the patterned TFC membranes. The real-time flux data for all of the samples are provided in the supplementary material (Fig. S4).

Table 3. Permeate flux and salt rejection of the TFC membranes; the $\mathrm{NaCl}$ concentration was $1 \mathrm{~g} / \mathrm{L}\left(\mathrm{pH}=7, \mathrm{TMP}=689.5 \mathrm{kPa}\right.$, and $\left.T=25 \pm 1^{\circ} \mathrm{C}\right)$.

\begin{tabular}{|c|c|c|c|c|}
\hline $\begin{array}{c}\text { UF } \\
\text { support }\end{array}$ & $\begin{array}{l}t_{i p} \\
(\mathbf{s})\end{array}$ & $\begin{array}{c}\text { MPD concentration } \\
(\text { wt } \%)\end{array}$ & $\begin{array}{l}\text { Permeate flux a } \\
\quad\left(\mathrm{Lm}^{-2} \mathbf{h}^{-1}\right)\end{array}$ & $\begin{array}{c}\text { Salt rejection } \\
(\%)\end{array}$ \\
\hline \multirow{3}{*}{ Flat } & 8 & 2 & $38.5 \pm 2.5$ & $76.6 \pm 3.5$ \\
\hline & 8 & 0.1 & $34.5 \pm 2.5$ & $80.4 \pm 1.8$ \\
\hline & 8 & 0.01 & $32.3 \pm 1.7$ & $77.5 \pm 2.5$ \\
\hline \multirow{6}{*}{ Sub-2 } & 8 & 2 & $40.2 \pm 3.3$ & $79.5 \pm 2.6$ \\
\hline & 16 & 2 & $41.5 \pm 3.8$ & $81.4 \pm 2.8$ \\
\hline & 32 & 2 & $39.5 \pm 2.9$ & $79.5 \pm 2.7$ \\
\hline & 120 & 2 & $35.5 \pm 3.6$ & $78.5 \pm 1.9$ \\
\hline & 8 & 0.1 & $40.2 \pm 2.6$ & $80.3 \pm 2.5$ \\
\hline & 8 & 0.01 & $39.5 \pm 3.6$ & $78.3 \pm 3.6$ \\
\hline
\end{tabular}

a The flux is taken as the mean value during the first $2 \mathrm{~h}$ of filtration. 
Overall, all of the TFC membranes appear to have similar rejection values ranging from $76 \%$ to $81 \%$, which fall into the range between NF and RO membranes with similar barrier-layer chemistry. This observation is consistent with the nano-TA measurements of the barrier layer discussed above. It is noted that the relatively low salt rejection is attributed to the low operating pressure used in this study. Related experimental studies showed that rejection of a $\mathrm{NaCl}$ solution with similar concentration to the present work increased from $\sim 60 \%$ at $689 \mathrm{kPa}$ to $>90 \%$ at 3000 $\mathrm{kPa}[36]$. We utilized a relatively low operating pressure that enables testing of both the TFC membranes and the UF supports.

The flux values of all the membranes tested were within a $\pm 20 \%$ range. The patterned membranes evidenced higher flux values than those of the flat samples prepared under identical conditions. This difference could be attributed to the larger surface area of the patterned TFC

membranes (with other factors being equal). Although a more rigorous comparison must be based upon larger-sized patterned membranes in cross-flow conditions, the filtration measurements confirmed that a polyamide barrier layer was indeed formed on the patterned UF support even with MPD concentration as low as $0.01 \%$ and IP reaction time as short as $8 \mathrm{~s}$, which is consistent with other reports $[17,35]$.

\subsection{PIP/TMC system characteristics}

In addition to the MPD/TMC systems discussed above, we also examined PIP/TMC systems for fabricating patterned TFC membranes. The major difference between the two systems lies in the "tightness" of the barrier layer formed: the semi-aromatic barrier layer formed by the PIP/TMC system is known to be less dense than the full-aromatic barrier layer formed by the MPD/TMC system [15,19]. Similar to the MPD systems, the pattern heights of the PIP-based TFC membranes showed negligible dependence on $t_{i p}$ (up to $120 \mathrm{~s}$ examined). Representative SEM 
images and corresponding AFM scans for TFC membranes prepared with 2\% PIP solution and sub-2 supports are shown in Fig. 8. These surface patterns appeared to be uniform and smooth (insignificant roughness along the patterned lines).

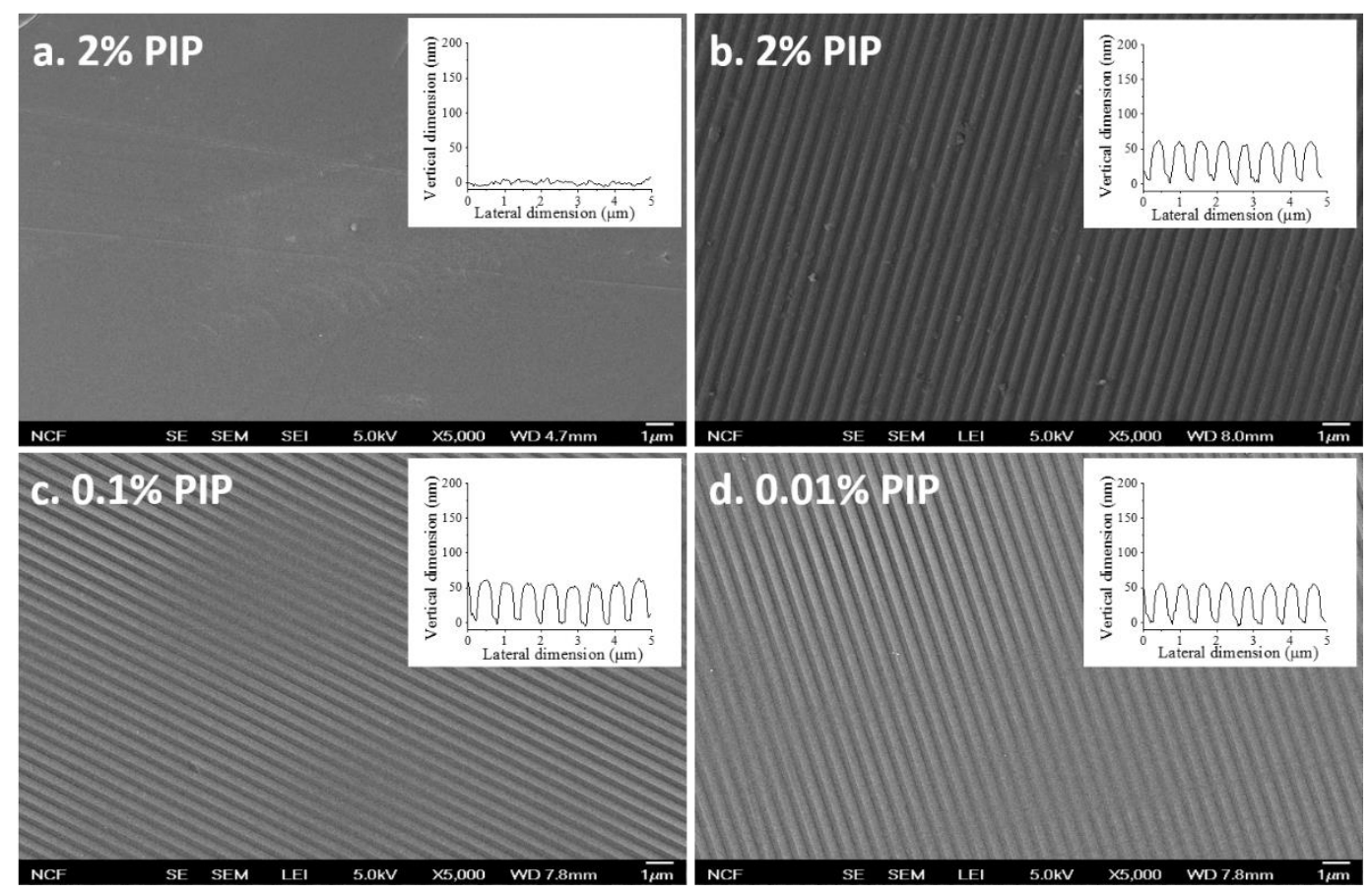

Figure 8. Representative SEM images of PIP-based TFC membranes obtained on (a) flat support with $2 \%$ PIP, and on sub-2 supports with different PIP concentrations: (b) $2 \%$, (c) $0.1 \%$, and (d) $0.01 \%$. Insets are the corresponding AFM scan profiles. For all the membranes, $t_{a s}=120 \mathrm{~s}$ and $t_{i p}=8 \mathrm{~s}$.

Figure 9 shows the pattern height results obtained for the PIP/TMC membranes fabricated with different PIP concentrations $(2 \%, 0.1 \%$ and $0.01 \%)$ on the three different patterned UF supports. Similar to the MPD/TMC system result (Fig. 5), the pattern heights reported here are mean values for each of the four different $t_{i p}(8,16,32$, and $120 \mathrm{~s})$ intervals employed. Overall, the pattern heights of these TFC membranes were smaller than those of the corresponding UF supports, suggesting non-uniform thickness of the polyamide layer. The results also indicate that 
TFC membranes prepared with lower PIP concentration evidenced taller surface patterns as compared to their MPD counterparts.

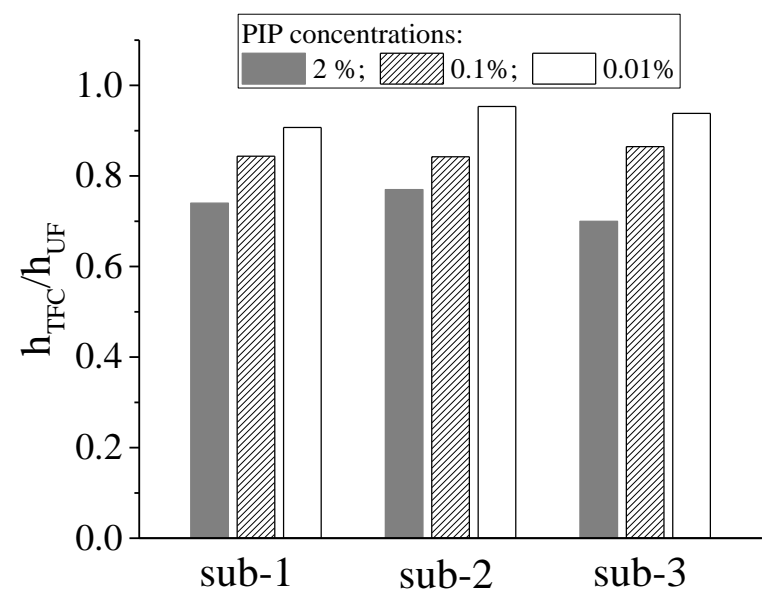

Figure 9. Ratio between the pattern heights of the TFC membranes $\left(h_{T F C}\right)$ and those of the corresponding UF support $\left(h_{U F}\right)$ for membranes fabricated with different PIP concentrations: $2 \%$ (solid bars), $0.1 \%$ (shaded bars), and $0.01 \%$ (empty bars). hTFC was the mean value for the membranes prepared with different $t_{i p}(8 \mathrm{~s}, 16 \mathrm{~s}, 32 \mathrm{~s}$, and $120 \mathrm{~s})$, but with identical PIP concentration and UF substrates. Accordingly, hUF represents the mean value of the four substrates used for the four different $t_{i p}$. For all these systems, the TMC concentration is $0.1 \%$ and $t_{a s}=120 \mathrm{~s}$.

Figure 10 shows representative TEM images of the TFC membranes prepared using three different concentrations of PIP. A smooth, continuous layer of polyamide with a thickness $\sim 10$ nm was observed for 2\% PIP on sub-2 (Fig. 10a). With a decrease of PIP concentration, the polyamide layers became too thin to be resolved (Fig.10b and 10c). By selectively dissolving the PES support, we were able to isolate continuous barrier layer films for the $2 \%$ PIP system, but the same technique could not be successfully applied to the $0.1 \%$ and $0.01 \%$ PIP membranes. These observations are similar to those for the MPD system discussed above. The major difference between the PIP- and MPD-based systems is that the barrier layer thickness remained uniform 
even for the 2\% PIP (Fig. 10a) membrane thus providing a relatively large $h_{U F} / h_{T F C}$ ratio as observed from AFM measurements (Fig. 9).
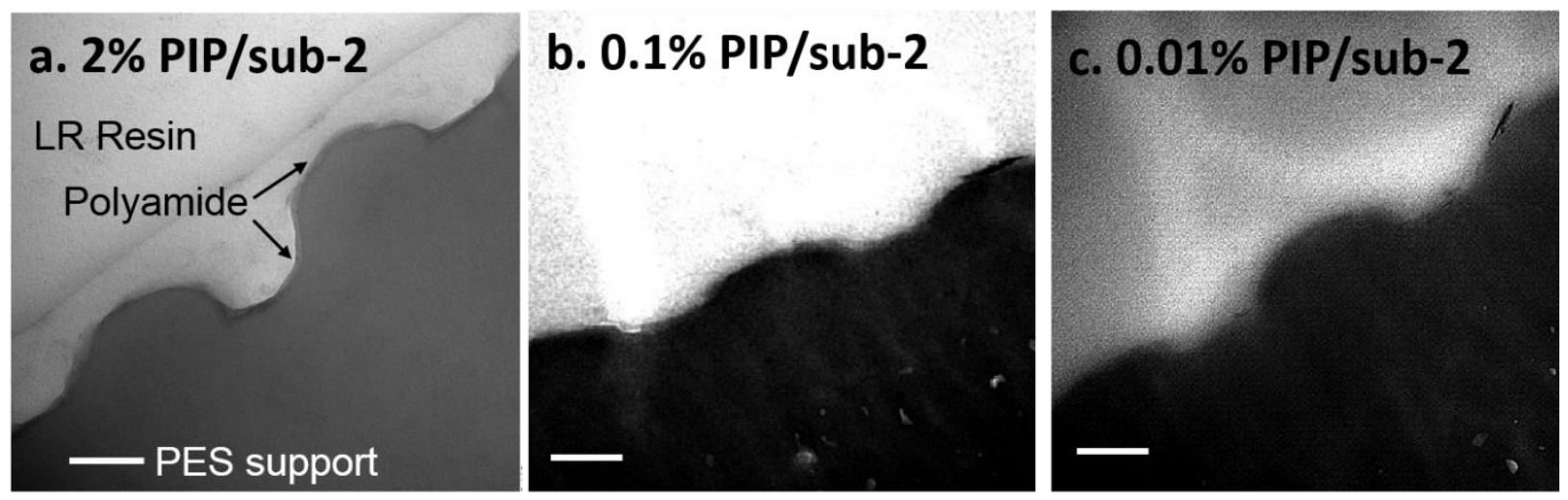

Figure 10. TEM images of TFC membranes fabricated on a sub-2 support with different PIP concentrations: (a) $2 \%$ PIP, (b) $0.1 \%$ PIP, and (c) $0.01 \%$ PIP. All membranes were fabricated with $t_{a s}=120 \mathrm{~s}$ and $t_{i p}=8 \mathrm{~s}$. Scale bars in (a)-(c) represent $100 \mathrm{~nm}$.

For the entire set of patterned TFC membranes examined in this study, the thickness of the IP polyamide layer was $<40 \mathrm{~nm}$ for the $2 \%$ MPD-based systems, $<15 \mathrm{~nm}$ for $2 \%$ PIP-based systems, and became too thin to be resolved for the MPD and PIP systems at lower concentrations. This range of thicknesses is consistent with several recent studies reporting barrier layer thickness in the range of 14-30 nm [37-40]. Moreover, the dense polyamide films formed in this study appeared to be void free, i.e. no empty "loops" between the barrier layer and the PES support were detected. This observation was true even for the $2 \%$ MPD system with $t_{i p}=150 \mathrm{~s}$, which started to develop a "nodular structure." (Fig S5). 
Table 4. Permeate flux and salt rejection of the TFC membranes prepared with PIP/TMC; the $\mathrm{NaCl}$ concentration was $1 \mathrm{~g} / \mathrm{L}\left(\mathrm{pH}=7.1, \mathrm{TMP}=689.5 \mathrm{kPa}, T=25 \pm 1{ }^{\circ} \mathrm{C}\right)$.

\begin{tabular}{|c|c|c|c|c|}
\hline $\begin{array}{c}\text { UF } \\
\text { support }\end{array}$ & $\begin{array}{c}\text { PIP concentration } \\
(\mathbf{w t} \%)\end{array}$ & $\begin{array}{l}t_{i p} \\
(\mathbf{s})\end{array}$ & $\begin{array}{l}\text { Permeate flux a } \\
\qquad\left(\mathbf{L m}^{-2} \mathbf{h}^{-1}\right)\end{array}$ & $\begin{array}{c}\text { Salt rejection } \\
(\%)\end{array}$ \\
\hline \multirow{3}{*}{ Flat } & 2 & 8 & 43.5 & 71.6 \\
\hline & 0.1 & 8 & 49.2 & 70.3 \\
\hline & 0.01 & 8 & 50.8 & 63.3 \\
\hline \multirow{3}{*}{ Sub-2 } & 2 & 8 & 46.4 & 73.4 \\
\hline & 0.1 & 8 & 54.4 & 72.8 \\
\hline & 0.01 & 8 & 54.2 & 68.3 \\
\hline
\end{tabular}

${ }^{a}$ The flux is taken as the mean value during the first $2 \mathrm{~h}$ of filtration; real time flux data is provided in the supplementary material.

Filtration measurements with $\mathrm{NaCl}$ solutions indicated that flat and patterned PIP/TMC TFC membranes had salt rejection values between $63 \%$ and $73 \%$ (Table 4); these values are lower than for the membranes fabricated from the MPD systems (Table 3). Correspondingly, the overall permeate flux for the PIP-based TFC membranes was higher than that of the MPD-based membranes. From nano-TA measurements, the $T_{g}$ of the barrier layer formed from the $2 \%$ PIP system was $\sim 138^{\circ} \mathrm{C}$ (Fig. S3b), which is much lower than that of the MPD-based systems but comparable with reported bulk $T_{g}$ values for the PIP-based polyamide $[41,42]$. These observations are consistent with the above TEM measurements as well as literature reports indicating that the PIP-based polyamide layers are normally thinner and less dense than the MPD-based ones [15,18].

\section{Conclusions}

In this study we experimentally examined the influence of the substrate topography and IP process variables on the characteristics of the resulting patterned TFC membranes. Surface patterned UF substrates with different pattern heights but identical periodicity were fabricated by adjusting the NIL process conditions. IP atop these patterned substrates was employed to form the desired barrier layers using both MPD and PIP amine systems. For all of the TFC membranes fabricated, surface patterns with low local roughness were achieved when the amine soaking time 
and IP reaction time were within 120 s. An important finding of the work was that the average height of the surface patterns appeared to be independent with the IP reaction time within this 120 s interval.

For all compositions examined, the pattern heights of the TFC membranes were less than those of the corresponding UF substrates, suggesting non-conformal growth of the barrier layer atop the patterned UF substrates. Such non-conformal growth can be reduced by reducing amine concentration and the use of amines that are known to produce thinner barrier layers such as PIP. As a result, TFC membranes prepared with low concentration PIP evidenced pattern heights that nearly matched those of the corresponding UF supports. These experimental findings suggest that surface topography of patterned TFC membranes can be controlled by adjusting the chemistry and kinetics of IP process as well as the topography of the UF support (via NIL), which is crucial for achieving targeted surface features for specific applications. The innovative use of patterned UF substrates allows scalable fabrication of patterned TFC membranes using current manufacturing routes, although process optimization is likely needed for achieving uniform patterns with a low concentration of defects.

Acknowledgements The authors gratefully acknowledge funding support from the National Science Foundation under Grant No. CBET-1264276, CMMI-1233626 and IIP- 1432952. The authors also gratefully acknowledge the National Science Foundation (NSF) Industry/University Cooperative Research Center for Membrane Science, Engineering and Technology (MAST) at the University of Colorado at Boulder (CU-B) for support of this research via NSF Award IIP 1034720. 


\section{References}

[1] A.D. Khawaji, I.K. Kutubkhanah, J.M. Wie, Advances in seawater desalination technologies, Desalination 221 (2008), 47-69.

[2] W.J. Lau, S. Gray, T. Matsuura, D. Emadzadeh, J. Paul Chen, A.F. Ismail, A review on polyamide thin film nanocomposite (TFN) membranes: History, applications, challenges and approaches, Water Res. 80 (2015) 306-324.

[3] M.M. Pendergast, E.M.V. Hoek, A review of water treatment membrane nanotechnologies, Energy Environ. Sci. 4 (2011) 1946-1971.

[4] M. Elimelech, W.A. Phillip, The future of seawater desalination: energy, technology, and the environment, Science 333 (2011) 712-717.

[5] R. Field, Fundamentals of fouling, in: K.V. Peinemann, S.P. Nunes (Eds.), Membr. Technol., Wiley-VCH Verlag GmbH \& Co. KGaA, 2010: pp. 1-23.

[6] D. Rana, T. Matsuura, Surface modifications for antifouling membranes, Chem. Rev. 110 (2010) 2448-2471.

[7] Y.K. Lee, Y.J. Won, J.H. Yoo, K.H. Ahn, C.H. Lee, Flow analysis and fouling on the patterned membrane surface, J. Membr. Sci. 427 (2013) 320-325.

[8] S.H. Maruf, A.R. Greenberg, J. Pellegrino, Y. Ding, Critical flux of surface-patterned ultrafiltration membranes during cross-flow filtration of colloidal particles, J. Membr. Sci. 471 (2014) 65-71.

[9] S.H. Maruf, M. Rickman, L. Wang, J. Mersch IV, A.R. Greenberg, J. Pellegrino, Influence of sub-micron surface patterns on the deposition of model proteins during active filtration, J. Membr. Sci. 444 (2013) 420-428.

[10] S.H. Maruf, L. Wang, A.R. Greenberg, J. Pellegrino, Y. Ding, Use of nanoimprinted surface patterns to mitigate colloidal deposition on ultrafiltration membranes, J. Membr. Sci. 428 (2013) 598-607.

[11] S.H. Maruf, Z. Li, J.A. Yoshimura, J. Xiao, A.R. Greenberg, Y. Ding, Influence of nanoimprint lithography on membrane structure and performance, Polymer. 69 (2015) 129137. 
[12] S.H. Maruf, A.R. Greenberg, J. Pellegrino, Y. Ding, Fabrication and characterization of a surface-patterned thin film composite membrane, J. Membr. Sci. 452 (2014) 11-19.

[13] J.E. Cadotte, R.J. Petersen, R.E. Larson, E.E. Erickson, A new thin-film composite seawater reverse osmosis membrane, Desalination 32 (1980) 25-31.

[14] G.Y. Chai, W.B. Krantz, Formation and characterization of polyamide membranes via interfacial polymerization, J. Membr. Sci. 93 (1994) 175-192.

[15] C. Bellona, J.E. Drewes, P. Xu, G. Amy, Factors affecting the rejection of organic solutes during NF/RO treatment — a literature review, Water Res. 38 (2004) 2795-2809.

[16] W.J. Lau, A.F. Ismail, N. Misdan, M.A. Kassim, A recent progress in thin film composite membrane: A review, Desalination 287 (2012) 190-199.

[17] Y. Song, P. Sun, L.L. Henry, B. Sun, Mechanisms of structure and performance controlled thin film composite membrane formation via interfacial polymerization process, J. Membr. Sci. 251 (2005) 67-79.

[18] V. Freger, Nanoscale heterogeneity of polyamide membranes formed by interfacial polymerization, Langmuir 19 (2003) 4791-4797.

[19] F.A. Pacheco, I. Pinnau, M. Reinhard, J.O. Leckie, Characterization of isolated polyamide thin films of RO and NF membranes using novel TEM techniques, J. Membr. Sci. 358 (2010) 51-59.

[20] Y.J. Won, S.Y. Jung, J.H. Jang, J.W. Lee, H.R. Chae, D.C. Choi, et al., Correlation of membrane fouling with topography of patterned membranes for water treatment, J. Membr. Sci. 498 (2016) 14-19.

[21] L.M. Cox, J.P. Killgore, Z. Li, Z. Zhang, D.C. Hurley, J. Xiao, et al., Morphing metalpolymer Janus particles, Adv. Mater. 26 (2014) 899-904.

[22] Z. Wang, C. Hansen, Q. Ge, S.H. Maruf, D.U. Ahn, H.J. Qi, et al., Programmable, patternmemorizing polymer surface, Adv. Mater. 23 (2011) 3669-3673.

[23] A.K. Ghosh, B.H. Jeong, X. Huang, E.M.V. Hoek, Impacts of reaction and curing conditions on polyamide composite reverse osmosis membrane properties, J. Membr. Sci. 311 (2008) 34-45. 
[24] S.P. Sun, T.S. Chung, K.J. Lu, S.Y. Chan, Enhancement of flux and solvent stability of Matrimid ${ }^{\circledR}$ thin-film composite membranes for organic solvent nanofiltration, AICHE J. 60 (2014) 3623-3633.

[25] S.H. Maruf, D.U. Ahn, J. Pellegrino, J.P. Killgore, A.R. Greenberg, Y. Ding, Correlation between barrier layer $\mathrm{Tg}$ and a thin-film composite polyamide membrane's performance: Effect of chlorine treatment, J. Membr. Sci. 405-406 (2012) 167-175.

[26] S.H. Maruf, D.U. Ahn, A.R. Greenberg, Y. Ding, Glass transition behaviors of interfacially polymerized polyamide barrier layers on thin film composite membranes via nano-thermal analysis, Polymer 52 (2011) 2643-2649.

[27] S. Belfer, R. Fainchtain, Y. Purinson, O. Kedem, Surface characterization by FTIR-ATR spectroscopy of polyethersulfone membranes-unmodified, modified and protein fouled, J. Membr. Sci. 172 (2000) 113-124.

[28] J. Coates, Interpretation of Infrared Spectra, A Practical Approach, in: R.A. Meyers (Ed.), Encyclopedia of analytical chemistry, John Wiley \& Sons Ltd., UK, Chicester, 2000.

[29] R.M. Silverstein, G.C. Bassler, Spectrometric identification of organic compounds, J. Chem. Educ. 39 (1962) 546.

[30] N. Misdan, W.J. Lau, A.F. Ismail, T. Matsuura, D. Rana, Study on the thin film composite poly(piperazine-amide) nanofiltration membrane: Impacts of physicochemical properties of substrate on interfacial polymerization formation, Desalination 344 (2014) 198-205.

[31] J. Xiang, Z. Xie, M. Hoang, K. Zhang, Effect of amine salt surfactants on the performance of thin film composite poly(piperazine-amide) nanofiltration membranes, Desalination 315 (2013) 156-163.

[32] V. Freger, Swelling and morphology of the skin layer of polyamide composite membranes: An atomic force microscopy study, Environ. Sci. Technol. 38 (2004) 3168-3175.

[33] J. Ji, J.M. Dickson, R.F. Childs, B.E. McCarry, Mathematical model for the formation of thin-film composite membranes by interfacial polymerization: porous and dense films, Macromolecules 33 (2000) 624-633. 
[34] R. Oizerovich-Honig, V. Raim, S. Srebnik, Simulation of thin film membranes formed by interfacial polymerization, Langmuir 26 (2010) 299-306.

[35] T.D. Matthews, H. Yan, D.G. Cahill, O. Coronell, B.J. Marinas, Growth dynamics of interfacially polymerized polyamide layers by diffuse reflectance spectroscopy and Rutherford backscattering spectrometry, J. Membr. Sci. 429 (2013) 71-80.

[36] W. Zhou, L. F. Song, Experimental study of water and salt flux through reverse osmosis membranes, Environ. Sci. Tech. 39 (2005) 3382-3387.

[37] T. Kamada, T. Shintani, T. Tsuru, T. Yoshioka, C. Kong, Composite separation membrane and separation membrane element using same, WO/2011/102124, 2011.

[38] S. Karan, Z. Jiang, A.G. Livingston, Sub-10 nm polyamide nanofilms with ultrafast solvent transport for molecular separation, Science 348 (2015) 1347-1351.

[39] I.J. Roh, V.P. Khare, Investigation of the specific role of chemical structure on the material and permeation properties of ultrathin aromatic polyamides, J. Mater. Chem. 12 (2002) 2334-2338.

[40] H. Yan, X. Miao, J. Xu, G. Pan, Y. Zhang, Y. Shi, et al., The porous structure of the fullyaromatic polyamide film in reverse osmosis membranes, J. Membr. Sci. 475 (2015) 504510.

[41] P.W. Dufton, Rapra Technology limited, industry analysis and business publishing group, Speciality and high performance rubbers: Materials in use and their marketplace : a report from Rapra’s industry analysis group, iSmithers Rapra Publishing, UK, Shropshire, 1997.

[42] R. Rulkens, Semi-aromatic polyamide, US20130150525 A1, 2013. 


\section{Graphic Abstract}
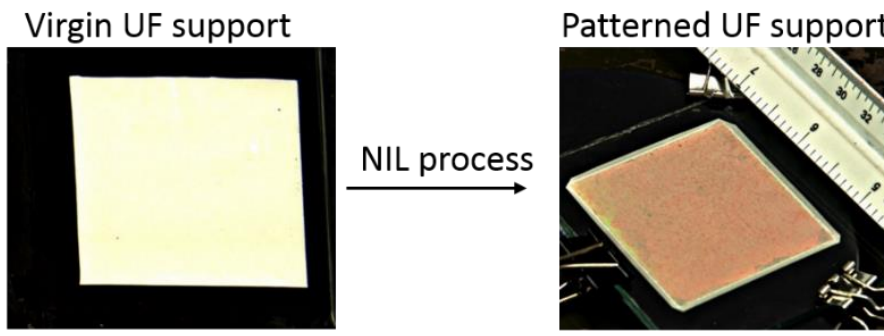

Patterned TFC membrane
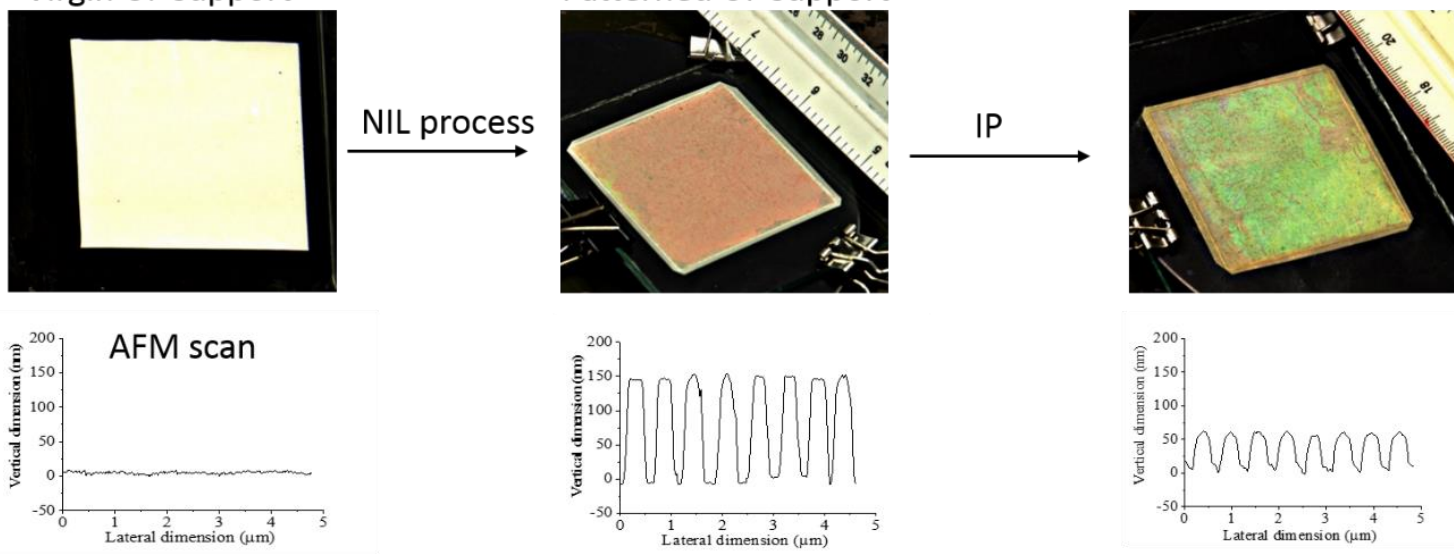

Top row: photographs showing the virgin membrane, the as-fabricated UF support (with surface patterns) by NIL, and the as-fabricated TFC membrane with IP. Bottom row: the corresponding AFM scans of the three membrane samples. 